\title{
Het vrije woord en de ideologie van de multiculturele samenleving*
}

\section{Bij wijze van inleiding, een wekroep.}

1. Na de bezorgde lezing door onze Noord-Nederlandse collega Cliteur (The Nature and Limits of Academic Freedom in a multicultural society, http://www.fondationuniversitaire.be/common_docs/Cliteur.doc) wil ik op mijn beurt graag een antwoord proberen te geven op de vraag naar de staat van de vrijheid van meningsuiting in dit land met betrekking tot de zogenaamde problematiek van de multiculturele samenleving.

Laat mij maar dadelijk zeggen dat het antwoord op de vraag of die vrijheid van meningsuiting rechtens nog bestaat in dit land m.i. duidelijk neen is. Die vrijheid wordt in ons land weliswaar nog niet vermoord met kogels. Doch in andere opzichten is het in ons land nog slechter gesteld: het is niet één of andere doorgeslagen terrorist die de vrijheid hier inperkt, maar de overheid zelf, de staat, de regering, het gerechtelijk apparaat dat precies tot taak zou moeten hebben die vrijheid te beschermen. Een steeds groeiend deel van de Vlaamse bevolking heeft dan ook terecht het gevoel dat de vrijheid van meningsuiting inzake de multiculturele samenleving sinds enige tijd niet meer geldt.

2. Die vrijheid is in het bijzonder afgeschaft in de volgende omstandigheden:

"in openbare bijeenkomsten of plaatsen; in tegenwoordigheid van verscheidene personen, in een plaats die niet openbaar is, maar toegankelijk voor een aantal personen die het recht hebben er te vergaderen of ze te bezoeken; in om het even welke plaats, in tegenwoordigheid van de beledigde en voor getuigen; in geschriften, al dan niet gedrukt, prenten of zinnebeelden, die aangeplakt, verspreid of verkocht, te koop geboden of openlijk tentoongesteld worden; en zelfs in geschriften, die niet openbaar gemaakt, maar aan verscheidene personen toegestuurd of meegedeeld worden."

Dat is immers de ruime definitie van "openbaar" in het Belgisch Strafwetboek. En in al die omstandigheden is het volgens de Belgische wet verboden om aan te zetten tot discriminatie of haat jegens een persoon, een groep, een gemeenschap of de leden ervan wegens een zogenaamd ras, zijn huidskleur, afkomst of nationale of etnische afstamming, en zelfs verboden om nog maar openbaar het voornemen tot discriminatie of haat te uiten, waarbij reeds als discriminatie geldt "elke vorm van onderscheid, uitsluiting, beperking of voorkeur, die tot doel heeft of ten gevolge heeft of kan hebben dat de erkenning, het genot of de uitoefening op voet van gelijkheid van de rechten van de mens en de fundamentele vrijheden op politiek, economisch, sociaal of cultureel terrein of op andere terreinen van het maatschappelijk leven, wordt teniet gedaan, aangetast of beperkt".

\footnotetext{
* Nader uitgewerkte versie van een lezing op het 3rd Ethical Forum van de Universiatire Stichting, Brussel 25 november 2004 "Free to speak out? On the rights and responsibilities of academics in the public debate". Het onderdeel over de specifieke verantwoordelijkheden van academici werd niet uitgewerkt, daar het in andere bijdragen uitvoeriger aan bod komt.
} 
3. Die bepaling criminaliseert dus wel degelijk loutere meningsuitingen. Zoals ze door de Belgische onrechtspraak wordt uitgelegd, verbiedt zij openbaar verkondigde meningen waarin getwijfeld wordt aan alvast één aspect van de nieuwe staatsgodsdienst. Die nieuwe godsdienst is de godsdienst van het multiculturalisme ${ }^{1}$. Een van de belangrijkste dogmata van die nieuwe godsdienst is precies de zogenaamd multiculturele samenleving - niet als een feitelijk begrip, maar als iets wat normatief wordt opgelegd als een te belijden ideaal. Dat ideaal is een dogma geworden dat niet meer in vraag wordt gesteld. Vandaar dat precies in het openbaar geuite afwijkende meningen over het onderscheid tussen mensen naargelang hun afkomst of gemeenschap waartoe ze behoren meer nog dan elke andere afwijkende mening moet worden bestreden. En dat bestrijden gebeurt niet met woorden - want daartoe heeft eenieder voor mij natuurlijk wel het recht - maar met georganiseerd geweld, namelijk gevangenisstraf en andere penale sancties.

Dat die bepaling, zoals ze wordt geïnterpreteerd, niet alleen hatelijk gedag criminaliseert maar ook loutere meningsuitingen, blijkt duidelijk uit het beruchte arrest van het Hof van beroep te Gent van 21 april 2004 - bevestigd door het Hof van cassatie op 9 november 2004 -: er is reeds een misdrijf door het loutere feit in het openbaar te pleiten voor een discriminerende wetswijziging, dit is een wetswijziging die in bepaalde opzichten een onderscheid makt tussen categorieën van mensen naargelang hun afkomst of zelfs hun nationaliteit, wanneer dat onderscheid volgens de rechter niet redelijk en objectief is verantwoord ${ }^{2}$. Ook wie stelt dat de bestaande wetten moeten worden geëerbiedigd, maar wel tegelijk pleit voor een wijziging van de wet in die zin, is dus strafbaar. De teksten van het EVRM en het Handvest van grondrechten in de Europese grondwet zijn vandaag gesacraliseerd tot heilige teksten die misschien nog wel op blote lijven mogen worden geschreven, maar waarvan de invraagstelling verboden is en zelfs strafrechtelijk wordt gesanctioneerd ${ }^{3}$. Nog juister is misschien te zeggen dat het niet de grondrechten zijn die gesacraliseerd zijn, maar het gelijkheidsbeginsel. In naam van dat gelijkheidsbeginsel worden echte grondrechten zoals de vrijheid van meningsuiting afgeschaft.

4. Door de genoemde wet wordt aan alle burgers de plicht opgelegd om voortdurend mee te bouwen aan het "op voet van gelijkheid" garanderen van hetzelfde genot van rechten aan iedereen. Welnu, zoals ik elders heb uitgewerkt is het juist een van de basiskenmerken van een totalitaire staat dat er geen onderscheid meer wordt gemaakt tussen de plichten van de overheid en die van de burger, dat de burger geen enkele

\footnotetext{
${ }^{1}$ Een ander aspect van deze nieuwe godsdienst kwam maanden na deze lezing aan de oppervlakte. In een zomer 2005 bekendgemaakt zogenaamd charter van de democratie wil het paars bewind aan alle burgers een akte van geloof in abortus, euthanasie en homohuwelijk opleggen.

2 Arrest 21 april 2004 inzake CGKR t. Vlaamse concentratie, punt 2.2.1.: "Wat het "aanzetten" betreft, is het zo dat een algemene aanmoediging tot het bedrijven van discriminatie, rassenscheiding, haat of geweld reeds volstaat. Een ten aanzien van medeburgers in de openbaarheidvereisten van het artikel 444 van het Strafwetboek gehouden pleidooi voor een discriminerende wetswijziging kan derhalve, ook al kan dergelijke wetswijziging slechts tot stand komen op de door de Grondwet voorziene wijze, ongetwijfeld als een algemene aanmoediging tot het bedrijven van discriminatie worden aangezien."

${ }^{3}$ Althans wanneer die invraagstelling in een richting gaat van een onderscheid dat door het regime als niet redelijk verantwoord wordt beschouwd. Discriminatie van mensen wegens hun politieke overtuiging bv. is zelfs een officiële politiek.
} 
andere vrijheid meer heeft dan de overheid. Kort gezegd: dat de burger niet meer de vrijheid heeft om te discrimineren, de fundamenteelste van alle vrijheden ${ }^{4}$.

Dat deze nefaste tendens niet alleen in de Belgische wetgeving aanwezig is, blijkt uit een ander voorbeeld, namelijk de anti-misbruikbepaling (art. II-114 ${ }^{5}$ ) van het Handvest van grondvesten in het ontwerp van Europese grondwet (http://europa.eu.int/eur-lex/lex/JOHtml.do?uri=OJ:C:2004:310:SOM:NL:HTML).

Die bepaling stelt dat geen van die rechten en vrijheden gebruikt mogen worden om ook maar één ervan af te schaffen of te beperken. Als men weet wat er intussen allemaal al tot mensenrecht gepromoveerd is, zoals bv. het recht op betaalde vakantie, dan betekent dit dat na goedkeuring van die grondwet er geen vrijheid van meningsuiting meer is om het recht op betaalde vakantie aan te vallen. Zo zou men ook niet meer mogen bepleiten dat menselijk bloed een verkoopbaar goed moet zijn. Een van de bepalingen uit het Handvest is immers dat het verboden is om bloed te verkopen. In dezelfde zin zal men niet langer de stelling mogen verdedigen dat het nastreven van een hoog niveau van consumentenbescherming in sommige aangelegenheden nonsensicaal is. Uit deze voorbeelden ziet men dat het een kwalijke gewoonte is om over "de mensenrechten" te spreken, terwijl zich binnen die categorie rechten van zeer uiteenlopend gehalte en belang bevinden. De term "mensenrechten" komt er eigenlijk op neer dat men de echte fundamentele vrijheden zoals de vrijheid van geweten, meningsuiting, godsdienst en vereniging verdrinkt en inperkt door ze te verlagen tot het niveau van allerlei andere zogenaamde rechten. In ieder geval is die ene zogenaamde misbruikbepaling van de ontwerp-grondwet al voldoende abject om dat Charter en daarmee ook die hele grondwet te verwerpen, omdat ze een nieuwe vorm van totalitarisme, een nieuw soort secularistische theocratie bekrachtigt.

5. Deze afschaffing van de vrijheid van meningsuiting wordt onder druk van de overheid ook doorgevoerd in de academische wereld. De zogenaamde antidiscriminatieverklaring van de Universiteit Gent $^{6}$ bevat een verregaande beperking van de meningsvrijheid, tot en met bepalingen die gelijk luiden met wetsbepalingen die door het grondwettelijk Hof ongrondwettig zijn verklaard. En vanzelfsprekend zijn er altijd wel academici te vinden die in plaats van er een punt van eer van te maken de vrijheid van denken te verdedigen, collaboreren aan die repressie, ze legitimeren, en ertoe aanzetten.

Behalve de meningsbreidel door de regering en het gerechtelijk apparaat, is er ook de vaak nog verregaander publieke intimidatie van "afwijkende meningen" door de weldenkenden van onze maatschappij.

Ik ben hoogleraar in de rechten. Het is dus mijn professionele taak om rechtsontwikkelingen, inbegrepen rechterlijke beslissingen, kritisch te

\footnotetext{
4 "De fundamenteelste vrijheid: de vrijheid om te discrimineren", Molinarilezing bij de ontvangst van de Prijs voor de vrijheid, Vivat Academia 2005, nr. 126, p. 3-27 en in Teksten, Kommentaren en Studies (TeKoS) 2005 nr. 118, p. 3-14, ook op http://www.storme.be/vrijheidsprijs.html.

5 "Geen van de bepalingen van dit Handvest mag worden uitgelegd als zou zij het recht inhouden enige activiteit te ontplooien of enige daad te verrichten met als doel de in dit Handvest erkende rechten of vrijheden teniet te doen of de rechten en vrijheden verdergaand te beperken dan door dit Handvest is toegestaan."

${ }^{6}$ http://www.ugent.be/nl/univgent/bestuur/vademecum/algemeen/verklaringen/antidiscriminatie.htm.
} 
becommentariëren. Ik moet toegeven dat ik het niet meer durf te zeggen en te schrijven wat ik denk van sommige rechterlijke beslissingen, zoals in het bijzonder het cassatie-arrest van 9 november 2004 in de zaak van het Centrum voor Gelijke Kansen en racismebestrijding - een overheidinstelling die is opgericht om de fundamentele vrijheden met overheidsgeld te lijf te gaan - tegen de Vlaamse concentratie. Niet alleen zou ik woorden te kort komen, ik durf ze ook niet te publiceren, omdat ik het me als advocaat in dit land niet kan permitteren ${ }^{7}$.

\section{De kern van de zaak: een dubbel onderscheid}

6. Nadat ik U hopelijk wakker heb gemaakt, probeer ik de kern van de zaak even samen te vatten. En die kern van de zaak vertrekt bij een dubbel onderscheid: enerzijds het onderscheid tussen recht en moraal en anderzijds het onderscheid tussen de vrijheid van de burger en die van de overheid. Die twee onderscheidingen vormen de essentie van het verschilt tussen een totalitaire maatschappij en een vrije democratische samenleving: de eerste maakt die twee onderscheidingen niet of nauwelijks, van de tweede vormen ze het belangrijkste fundament.

7. Het totalitarisme wordt bovenal gekenmerkt door een duidelijk onderscheid tussen goed en kwaad; datgene wat als goed geldt moet dan ook worden opgelegd - desnoods met geweld - en wat als kwaad geldt bestreden in plaats van getolereerd ${ }^{8}$. In een democratie is er weinig zwart of wit en veel grijs, veel ruimte voor twijfel. In dubiis libertas. Die ruimte is het domein van de burgerlijke samenleving, niet van de staat. Het is de ruimte voor het morele debat, opengehouden door de juridische vrijheden.

Dit onderscheid tussen recht en moraal, en tussen staat en civil society, en de daarmee samenhangende fundamentele vrijheden, zijn belangrijke evolutionaire verworvenheden van het Westen. Ze zijn niet vanzelfsprekend, en dienen dan ook steeds opnieuw tegen totalitaire tendensen te worden verdedigd. Deze totalitaire tendensen vermommen zich daarbij maar al te vaak als verdedigers van het goede, als intolerante verdedigers van het goede. Want zoals de Joods-Nederlandse historicus Jacques Presser (http://nl.wikipedia.org/wiki/Jacques_Presser) het al enkele decennia

\footnotetext{
${ }^{7}$ Het volstond overigens dat ik nog maar in algemene bewoordingen kritiek had geuit op die rechtspraak of ik werd de volgende dag publiekelijk aangevallen door de voormalige directeur van datzelfde Centrum met het argument dat ik de scheiding der machten niet eerbiedigde. Nota Bene door de directeur van een centrum dat juist is opgericht in strijd met de grondwettelijke scheiding der machten en bevoegdheden heeft gekregen die normaal enkel aan de magistratuur toekomen. Die ging dus beweren dat een hoogleraar in de rechten, die betaald wordt om de rechtspraak kritisch te ontleden, precies dat niet meer zou mogen doen. De uitval toont trouwens opnieuw aan hoezeer het onderscheid tussen de positie van de staat en de burger is geperverteerd: men past hier opnieuw tegen de burger regels toe die bedoeld zijn om de burger tegen de staat te beschermen (nl. de scheiding tussen uitvoerende en rechterlijke macht).

${ }^{8}$ Over tolerantie, zie uitvoeriger mijn bijdrage "Tolerantie, lezing Nationaal Congres Davidsfonds, Antwerpen 20 april 2002, in "De Vlaamse Beweging.Welke toekomst?", Davidsfonds Leuven 2002, p. 164-179; licht gewijzigde versie in Nova et Vetera, Tijdschrift voor Onderwijs en Opvoeding, jg. LXXX, 2002-2003, nr. 6, p. 435-449; licht gewijzigd op http://www.storme.be/tolerantie.html.
} 
8. Het onderscheid tussen recht en moraal is in twee richtingen essentieel: op de eerste plaats betekent het dat de juridische vrijheid ook - ja zelfs vooral - de vrijheid omvat om door anderen immoreel geachte meningen te uiten. Zij mogen niet met geweld worden bestreden Maar even belangrijk is natuurlijk dat dit onderscheid ook betekent dat het morele debat niet door het recht wordt gesmoord: de juridische vrijheid om iets te doen of te zeggen is nog geen morele legitimatie. Zij verhindert anderen niet om die mening of gedraging immoreel te vinden en op geweldloze manier te bestrijden.

Vandaag de dag zien we echter meer en meer een perverse identificatie van recht en moraal:

- enerzijds leidt dit ertoe dat te veel fatsoensregels - bv. niet aanzetten tot haat - tot dwingende rechtsregels worden verheven - hypertrofie van de moraal -, wat het morele debat verstikt door het opleggen van te veel uniformiteit.

- maar omgekeerd leidt het er ook toe dat de niet afdwingbaar gestelde fatsoensregels elke morele aanspraak verliezen. Dit fenomeen zien we de laatste jaren sterk in de pervertering van het begrip "tolerantie", waarmee het burgers onmogelijk wordt gemaakt om dingen die ze immoreel achten nog geweldloos te bestrijden. Het meest uitgesproken voorbeeld daarvan is de criminalisering van de zogenaamde "homofobie"- begrip dat als knots gebruikt wordt om elk moreel debat te fnuiken.

Het is deze perversiteit die geleid heeft tot het wegsturen van de Italiaanse christendemocraat Rocco Buttiglione als eurocommissaris. De nieuwe europese staatsgodsdienst, de Eu-religie, aanvaardde namelijk niet meer het door hem gehanteerde onderscheid tussen misdrijf (recht) en zonde (moraal). Buttiglione aanvaarde als perfecte democraat dat wat zondig was nog niet moet verboden worden, de secularisten konden echter niet aanvaarden dat iemand iets wat niet wettelijk verboden was nog zonde mag vinden ${ }^{10}$.

9. Het is dus dringend tijd om meer ruimte te scheppen voor moreel zowel als politiek debat - ook inzake de zogenaamde multiculturele samenleving. Deze ruimte vereist het herstel van de vrijheid van meningsuiting, dus de afschaffing van alle wetgeving die zogenaamd racistische of discriminerende meningsuitingen verbiedt. Onfatsoenlijke meningen dient men niet te verbieden, maar door tegenmeningen te bestrijden. Iedereen heeft het recht om Rocco Buttiglione homofoob te noemen, net zoals ik het recht heb om iemand die het woord homofobie gebruik een intolerante en gevaarlijke fobomaan te noemen ${ }^{11}$; doch zodra homofobie in meningsuitingen een misdrijf is, leven we niet meer in een democratie maar in een totalitaire staat.

\footnotetext{
9 onder meer aangehaald door Michaël Zeeman in Knack 2003/8. Zie ook http://www.refdag.nl/artikel/20024/Woorden+leiden+soms+tot+kogels.html.

${ }^{10}$ Zie hierover nader mijn bijdrage "Ontslag Buttiglione illustreert machtsgreep Europese tegenreligie", volledig op http://www.storme.be/Buttiglione.html, licht ingekort in 't Pallieterke 9 november 2004, sterk ingekort in de Tijd 8 november 2004.

${ }^{11}$ Zie voor het begrip fobomanie mijn hoger geciteerde bijdrage "Tolerantie".
} 
Het is juist alleen maar door juridische vrijheid en morele verantwoording te onderscheiden, dus door onfatsoenlijke meningen niét te verbieden dat de vrijheidsruimte wordt gecreëerd om gedragingen of opvattingen van anderen die wij onethisch vinden ook als onethisch te bestrijden. Want een regime dat ermee begint alles wat onfatsoenlijk is juridisch te verbieden eindigt ermee alles wat niet juridisch verboden is tot fatsoenlijk uit te roepen en van anderen te eisen dat zij dit ook fatsoenlijk vinden. Het onderscheid tussen recht en moraal of fatsoen is dus een noodzakelijke mogelijkheidsvoorwaarde voor elk ethisch debat.

10. Het hedendaagse dogma van de multiculturele samenleving daarentegen, het dogma van het antiracisme, van de bestrijding van allerlei beweerde fobiëen zoals homofobie of islamofobie, heeft met multicultuur niets te maken, maar creëert een moreel nihilistische monocultuur, die ik elders ironisch het multinihilisme heb genoemd $^{12}$. Dit dogma houdt helemaal géén openheid in voor andere culturen of religies, want geen enkele van die andere culturen of religies aanvaardt het verregaande discriminatieverbod dat onder de vlag van multiculturalisme in het Westen is ingevoerd. Een multiculturele ingesteldheid zou immers precies het recht moeten inhouden om er andere morele opvattingen op na te houden dan de heersende, en om de al dan niet heersende opvattingen die men immoreel vindt op geweldloze manier te bestrijden. Het officiële multiculturalisme daarentegen komt er vandaag op neer dat culturele overtuigingen van onder meer etnische of religieuze minderheden waaraan deze vaak erg gehecht zijn, in het bijzonder in bio-ethische of sexuele materies, evenzeer gecriminaliseerd worden.

11. Het hier geschetste onderscheid tussen recht en moraal is ook een uiterst morele opvatting. Het is namelijk een zeer belangrijk aspect van de deugd der tolerantie. De ethiek vereist namelijk helemaal niet dat alles wat men kwaad acht ook moet verboden worden; het met geweld bestrijden van wat men kwaad acht is in de meeste gevallen een groter kwaad dan het tolereren ervan. Het via een wet of rechter verbieden van een onfatsoenlijke meningsuiting is in alle gevallen een groter kwaad dan die uiting zelf, voor zover het louter om een meningsuiting gaat: "De schade die het vrije woord ongetwijfeld berokkent is de prijs die betaald moet worden voor het grootste rechtsgoed dat een vrije samenleving kent" ${ }^{13}$. Het morele antwoord op onfatsoenlijke meningen kan enkel "more speech, not less speech" zijn.

Het gaat dus niet om een tegenstelling tussen recht en moraal, in die zin dat de rechtsorde in strijd mag zijn met de ethiek. Zij is enkel in strijd met de simplistische opvatting van ethiek die eigen is aan het totalitaire denken. Maar het is allesbehalve immoreel maar juist essentieel ethisch om de heersende moraliteit (d.i. die van de politieke machthebbers) in vele gevallen niet met rechtelijke geboden en verboden (en dus geweld) op te leggen. Een rechtsorde die onfatsoenlijke en zelfs immorele meningen en zelfs gedragingen tolereert, is een morele orde, want zij beoefent de deugd van de tolerantie; zij realiseert een complexere moraal dan de simplistische

12 In - "Opmars van het multinihilisme - Waarden om voor te vechten ?", Doorbraak december 2001, p. 3, en in "(Inter)nationalist zijn vandaag - tussen individualisme en totalitarisme, universalisme en particularisme, cultuurimperialisme en multiculturalisme, schizofrenie en paranoia", emeritaatsviering prof. Ponette, 6 oktober 2001, in Vivat Academia 2002, licht verkort in Civis Mundi 2002 nr. 1, p. 51-56, ook op http://www.storme.be/internationalisme.pdf.

${ }^{13}$ J. GRIFFITHS, "Geef mij meer fatsoen en minder recht", NJB 2004, 2336. 
moraal die van oordeel is dat alles wat onfatsoenlijk is ook door rechters en inquisiteurs, juridisch dus, moet worden bestreden.

\section{Juridische grenzen aan de meningsuiting?}

12. De in antiracisme- en antidiscriminatiewetten ingevoerde beperkingen aan de aldus niet meer vrije - meningsuiting zijn m.i. dus ethisch zowel als democratisch onaanvaardbaar. Ik heb het hier dus wel over juridische beperkingen die het mogelijk maken meningsuitingen met geweld te onderdrukken.

De vrije meningsuiting wordt door die breidelwetten in ons huidig regime vooral ingeperkt in zoverre de uiting een "aanzetten" vormt tot iets, en niet meer alleen, zoals vroeger in zeer beperkende voorwaarden (laster), omwille van de inhoud van de mening. Maar behalve bij het gebruik van geweld of dwang ligt tussen het aanzetten tot iets en de aangezette daad ligt nog de vrije wil van de persoon die aangezet wordt. Dat is een essentieel verschil met handelingen die op zichzelf schade berokkenen, of iemand anders dwingen schade te berokkenen (in welk geval het niet meer om aanzetten maar om dwingen gaat, wat een heel ander register is, omdat daar de vrijheid van de gedwongene rechtstreeks in het geding is; hier is er dus minstens sprake van misbruik van een machtspositie die men heeft over de persoon die aangezet wordt). Een samenleving die de mens als een wezen met vrije wil erkent, kan onmogelijk een uiting die zou aanzetten tot een onwettige gedraging zonder daartoe te dwingen, met die onwettige gedraging gelijkstellen - laat staan dat men nog van een democratische samenleving kan spreken wanneer het aanzetten tot onfatsoenlijke maar zelfs niet onwettige gedragingen kan worden gestraft (zoals vandaag in België).

13. Nog erger is het omdat de huidige wetgeving niet alleen het aanzetten tot geweld verbiedt - daar heb ik nog enig begrip voor, met name wanneer er een rechtstreekse bedreiging is voor de fysieke integriteit van personen. Maar ook het aanzetten tot haat wordt verboden, terwijl haat geen misdrijf is, maar een gevoel, dat overigens in bepaalde omstandigheden moreel volstrekt begrijpelijk kan zijn. Natuurlijk is haat in de meeste gevallen niet het meest fatsoenlijke gevoel. Het zal meestal een ondeugd zijn te haten en een deugd om geen haat te voelen. Maar het opleggen van die deugd en verbieden van die ondeugd is een veel grotere ondeugd dan het tolereren ervan. Iets hatelijk vinden en dat zeggen is overigens vanzelfsprekend een mening. "Haat is geen mening"14 is dan ook één van de belachelijkste argumenten die ik ooit gehoord heb in het debat over de vrije meningsuiting, een typisch voorbeeld van Newspeak. Het recht om te haten en het recht om lief te hebben zijn fundamentele rechten van elke persoon. Overigens is het vaak zo dat bij de verdedigers van het verbod op bepaalde meningen de haat jegens andersdenkenden ervan afdruipt. Van bepaalde rechterlijke uitspraken zoals het arrest van 21 april 2004 druipt de haat jegens andersdenkenden af. En als er één plaats is waar haat in een democratische

\footnotetext{
${ }^{14}$ Titel van een artikel van D. VOORHOOF, in De Standaard 7 mei 2004 (ook te vinden op http://www.mensenrechten.be/main.php?item content=106). De argumenten van de auteur zijn autoriteitsargumenten: het verbod op aanzetten tot haat of discriminatie volgt uit internationale zogenaamde mensenrechtenverdragen en wie zich daartegenover op de vrijheid van meningsuiting beroept maakt bij de rechters in Straatsburg toch geen kans. Ook hier vinden we de afdreiging in de trant van "durf het niet om de dogma's van de mensenrechten" en de interpretatie ervan door politieke benoemde rechter sin vraag te stellen.
} 
samenleving juist niet kan worden toegestaan, dan is het precies in rechterlijke uitspraken. Voor het overige erken ik graag eenieders recht om ook bepaalde meningen te haten, maar willen ze dan misschien een beetje consequent zijn en het verbod op aanzetten tot haat uit de wet schrappen?

14. Een al even schabouwelijke inperking van de meningsuiting betreft het verbod op het aanzetten tot discriminatie of het uiten van een voornemen tot discriminatie. Omdat ik specifiek dit aspect elders uitvoeriger heb besproken, ga ik er hier niet nader op in ${ }^{15}$.

15. Een inperking van de vrijheid van meningsuiting eis democratisch en ethisch enkel verantwoord wanneer de uiting een individuele persoon in zijn persoonlijke waardigheid treft. Maar het is nonsens om de belediging van een groep strafbaar te stellen. Er is een fundamenteel verschil tussen een algemene beledigende of valselijk beschuldigende uitspraak en een uitspraak die uitdrukkelijk een of meer bepaalde individuele personen beledigt of valselijk beschuldigt. Het "recht op goede naam" dat een beperking van de uitingsvrijheid rechtvaardigt, is een individueel recht van personen en géén collectief recht, zeker niet wanneer blijkt dat dit collectief recht blijkbaar alleen voor bepaalde soorten groepen geldt. Het is strijdig met de gelijkheid van de burgers om die beperkingen van de uitingsvrijheid, die de rechten van individuen beschermen, uit te breiden om "groepen" te beschermen. Daarmee kent men aan die groepen - met name goed georganiseerde groepen die erin slagen zich te laten erkennen als een beledigde of gediscrimineerde groep - allerlei collectieve rechten toe die de groep van gewone burgers niet heeft. Het kan dus niet dat meningsuitingen verboden zijn omdat zij krenkend zouden zijn voor een groep en niet voor een bepaalde persoon.

16. De verantwoordingen voor die inperking van de meningsuiting rammelen dus aan alle kanten, ook het argument van de bescherming van de rechten van anderen. Als het om de bescherming van anderen gaat zou men overigens de uiting van onfatsoenlijke meningen in het openbaar moeten verplichten in plaats van te verbieden. Onfatsoenlijke meningen zijn namelijk juist des te gevaarlijker naarmate ze niet meer in het openbaar geuit worden. De mogelijkheid gevoelens van haat of discriminerende opinies te uiten bespaart een samenleving veel gevaarlijker uitingen van opgekropte frustratie.

Dat onfatsoenlijke meningen juist met meer in plaats van minder meningsuiting moeten worden bestreden, maakt dan wel dat het perfect verantwoord is de rechten van personen te beschermen door hen een recht op antwoord toe te kennen en media een verplichting tot rechtzetting op te leggen. Daarmee wordt de vrijheid van meningsuiting immers niet aangetast.

\section{Morele grenzen}

17. Overigens zijn meningsuitingen m.i. niet alleen als dusdanig nooit juridisch te verbieden, maar ook op het ethische niveau niet te snel immoreel te noemen. Zoals de reeds genoemde de Brits-Nederlandse rechtsanthropoloog John Griffiths ${ }^{16}$ schrijft kan

\footnotetext{
15 "De fundamenteelste vrijheid: de vrijheid om te discrimineren", hoger aangehaald.

${ }^{16}$ J. GRIFFITHS, "Geef mij meer fatsoen en minder recht", NJB 2004, 2336.
} 
het misbruik - dat dus ook voor hem door de staat niet mag worden beperkt, maar wel door de burgers als onfatsoenlijk mag worden bestreden - niet bestaan uit de gedachte die ten grondslag ligt aan de uiting, maar enkel "in de onnodig kwetsende wijze waarop een gedachte wordt geuit. En het "onnodige" zit niet in de pijn die de gedachte zelf doet, maar in het ontbreken van enige communicatieve meerwaarde in de woorden of beelden die nodeloze pijn toevoegen: schuttingtaal, beladen termen zoals "nazi", heilige teksten op blote lijven, enzovoorts" - einde citaat. Ongeacht of men het met dit laatste voorbeeld eens is of niet, de kern van de zaak is moeilijk beter te verwoorden.

Ik vraag niet liever dan dat alle meningsuitingen binnen de grenzen van het fatsoenlijke zouden blijven. Maar hoe kan men tegelijk zeggen dat het volkomen onfatsoenlijk was van Theo Van Gogh om over geitenneukers te spreken - dat was het ook, ook al was het een toespeling op een advies van ayatollah Khomeini - en tegelijkertijd overheidscampagnes in de scholen te brengen die schuttingtaal promoten en allerlei verstrengelde blote lijven brengen zonder communicatieve meerwaarde. Hoe kan men tegelijk meningen verbieden omdat ze immoreel zouden zijn, maar tegelijk het choqueren van gelovigen tot officiële politiek maken, door een bewuste aanval op precies die zaken waaraan alle grote godsdiensten een bijzondere sacraliteit toekennen, zoals bv. het huwelijk ?

18. In ieder geval hebben we de vrijheid van meningsuiting precies nodig om onfatsoenlijke, onethische opvattingen (zowel als gedragingen) te bestrijden - te bestrijden met woorden, niet met geweld. Meer nog, in tegenstelling tot de overheid moet iedere burger precies de vrijheid hebben om anderen te discrimineren, onder meer omdat ze die ander onfatsoenlijk vinden. Die discriminatievrijheid is met andere woorden een noodzakelijke voorwaarde voor morele weerbaarheid.

\section{Beperking van de meningsuiting door private personen en organisaties.}

19. Consequent doorgedacht houdt het voorgaande ook in dat private organisaties personen mogen discrimineren wegens hun mening en op die wijze de vrije meningsuiting mogen inperken. Ik heb het recht in mijn huis iemand de deur te wijzen omdat wat hij zegt me niet aanstaat. Eenieder heeft de vrijheid te zeggen wat hij wil, maar elke private organisatie heeft de vrijheid hem om die reden niet in dienst te nemen, aan hem niet te leveren of bij hem niet aan te kopen, hem niet als lid te aanvaarden, e.d.m. Het kan uitermate onfatsoenlijk zijn om dat te doen, zoals ook het uiten ven bepaalde meningen onfatsoenlijk is. Maar het is ethisch volkomen gerechtvaardigd dat die vrijheid bestaat, omdat het inperken van die vrijheid moreel een groter kwaad is. Dit betekent niet dat we private personen en organisaties niet moreel ter verantwoording kunnen roepen, maar wel dat zij niet verplicht kunnen worden zich daarvoor in rechte te verantwoorden.

20. Diezelfde vrijheid geldt vanzelfsprekend niet voor de overheid, om de eenvoudige reden dat de overheid een monopoliepositie heeft, met name een geweldmonopolie. Keerzijde van dat monopolie zijn het legaliteitsbeginsel, dat het de overheid verbiedt anders te beslissen dan aan de hand van op voorhand bepaalde, voor iedereen gelijk geldende algemene regels en het verbod voor de overheid om te discrimineren (d.i. de eigen burgers ongelijk te behandelen zonder dit objectief en redelijk te rechtvaardigen). Dit zowel als de erkenning van vrijheidsruimten door de overheid 
heeft essentieel te maken met het feit dat de wet ook wordt opgelegd aan wie er niet mee instemt. Zonder die terughoudendheid is een democratie niets meer dan een dictatuur van de meerderheid.

Op de grens tussen beiden liggen private organisaties die weliswaar geen wettelijk, maar toch een feitelijk monopolie bezitten, alleen of met andere organisaties waarmee ze hun beleid afstemmen. Zolang een dergelijke situatie aanhoudt, is het verantwoord aan die organisaties vergelijkbare plichten op te leggen als aan de overheid.

\section{Toegepast op de universiteiten}

21. Laten we dit even toepassen op organisaties die voor academici natuurlijk van bijzonder belang zijn: onze Universiteiten. In beginsel moeten we dus een onderscheid maken tussen publieke en private universiteiten. De laatste kunnen bv. ideologische of religieuze eisen stellen bij de aanwerving van hun personeel. Zij kunnen ook eisen stellen aan de meningsuitingen van hun personeel. Zij moeten zich natuurlijk wel houden aan de regels die contractueel zijn afgesproken, maar kunnen in beginsel meningsuitingsbeperkende regels hanteren, althans wanneer die uitdrukkelijk zijn bedongen bij de aanwerving.

22. De vraag rijst evenwel of er in ons land nog sprake is van private universiteiten in de echte zin des woords, en of er in bepaalde opzichten geen feitelijk op vele vlakken elk alternatief uitsluit. Anders dan in de Verenigde Staten is het in ons land onmogelijk om zomaar een nieuwe private universiteit op te richten. De vraag is dus hoe groot de keuzevrijheid nog is. Indien met name alle Universiteiten zich "bekennen" tot de ideologie van het multiculturalisme heeft die ideologie daarmee een feitelijk monopolie op de markt van de universiteiten, en is het dus niet aanvaardbaar dat een universiteit iemand zou discrimineren omdat hij de officiële opvatting over het multiculturalisme niet deelt. Op andere vlakken geldt dat monopolie nog niet: het is dus nog steeds perfect aanvaardbaar dat een zich katholiek noemende universiteit religieuze eisen stelt aan haar personeel, precies omdat er op dat vlak voldoende alternatieven zijn. Jammer genoeg moeten we vaststellen dat de zich katholiek noemende universiteit in recente tijden weinig graten ziet in uitgesproken nietkatholieke opvattingen onder haar personeel, en veel meer problemen schijnt te hebben met opvattingen die afwijken van de staatsgodsdienst van multiculturalisme en non-discriminatie.

\section{De opdracht van de universiteit ter verdediging van de vrije meningsuiting}

23. Ik beschouw het daarentegen precies als een belangrijke taak voor onze universiteiten om meer dan welke instelling ook de vrijheid van meningsuiting te bevorderen en te vrijwaren. Ik vind het bedroevend om vast te stellen dat personen die zich lenen tot het verdrukken van de vrije meningsuiting een plaats hebben aan onze Universiteiten. en daarvoor nooit verontrust worden, wat niet kan gezegd worden van diegenen die juist hun nek uitsteken voor die vrijheid. De Universiteiten zouden juist weerstand moeten bieden aan de repressie door de overheid in plaats van er zich toe te lenen een dergelijke politiek mee uit te voeren. De Universiteiten moeten een 
vrijhaven zijn van het denken ${ }^{17}$. De daarmee strijdige bepalingen van allerhande antidiscriminatieverklaringen zijn een onaanvaardbare aanslag op die vrijheid van denken en spreken ${ }^{18}$.

De Universiteiten zouden zich integendeel moeten opwerpen als beschermheren van hun kritische professoren, wanneer die bv. door de media of door andere lobby's worden aangevallen. Natuurlijk moeten de Universiteiten niet de inhoud verdedigen van wat alle professoren vertellen - bespaar ons dat in Godsnaam - maar wel het feit dat zij de vrijheid hebben dat te zeggen. Zij zouden luidop moeten protesteren telkens wanneer de buitenwereld de inperking vraagt van de vrije meningsuiting van professoren of sancties vraagt tegen professoren die onwelgevallige meningen uiten. Naarmate de Universiteiten versagen in deze plicht, zullen de groepen die het luidst roepen of het meest intimideren door vrijdenkers van allerlei fobieën te beschuldigen, er steeds meer in slagen hun partijdige kijk op te dringen aan het publieke debat en worden de gedachten steeds minder vrij. Ik ben er al evenmin als Paul Cliteur gerust in.

\footnotetext{
${ }^{17}$ Natuurlijk hebben Universiteiten het recht en zelfs de plicht na te gaan of hun professoren hun taak vervullen, of ze naar behoren hun onderwijsopdrachten vervullen, onderzoek verrichten, of aan dienstverlening doen, of ze geen fraude plegen of tolereren, zich niet aan plagiaat bezondigen e.d.m. En natuurlijk houdt de vrijheid van meningsuiting van professoren niet in dat zij tijdens het onderwijs gelijk wat mogen zeggen, en hun colleges zouden mogen misbruiken om ideologische meningen te uiten die voor de opleiding van de studenten niet relevant zijn. En natuurlijk hebben de professoren ook een vorm van beroepsgeheim. De lezer zal ook wel beseffen dat het er hier niet daarom te doen is. Deze vragen komen in andere bijdragen aan dit Forum aan bod. (http://www.fondationuniversitaire.be/fr/forum3.php\#prog)

${ }^{18}$ Zo heeft de universiteit Gent de dictatuur van de politieke correctheid en de fobomanie al ingevoerd door het verbieden van "discriminerende stereotiepen en vooroordelen" in colleges en syllabusmateriaal en te eisen dat bij het formuleren van uitspraken en het aangaan van discussies "de mensenrechten" (welke ??) als leidraad dienen (zie art. 4 antidiscriminatieverklaring van 16 januari 2004). Op deze wijze wordt dus duidelijk één bepaalde ideologie als enige toegelaten in het onderwijs.
} 